\title{
Ascite neoplásica. Efeito da solução aquosa de fenol, ácido acético e glicerina sobre o tumor ascítico de Ehrlich ${ }^{1}$
}

\author{
Rogério Saad-Hossne ${ }^{2}$ \\ Willian Saad-Hossne ${ }^{3}$ \\ Renê Gamberini Prado ${ }^{2}$
}

\begin{abstract}
Saad-Hossne R, Hossne WS, Prado RG. Ascite neoplásica: efeito da solução aquosa de fenol, ácido acética e glicerina sobre o tumor ascítico de Ehrlich. Acta Cir Bras [serial online] 2003 Nov-Dez;18(6). Disponível em URL: http://www.scielo.br/acb.

RESUMO - Objetivo: Verificar o efeito da solução composta por fenol, ácido acético e glicerina sobre o tumor ascítico de Ehrlich. Métodos: Utilizou-se 283 camundongos divididos em 2 protocolos (animais portadores e não portadores de tumor) procedendo-se a injeção de $0,25 \mathrm{ml}, 0,10 \mathrm{ml}$ e $0,05 \mathrm{ml}$ da solução teste e $0,25 \mathrm{ml}$ de solução salina, o sacrifício foi realizado após 3 e 6 dias do tratamento, analisando, a seguir, a contagem diferencial de células presentes no líquido ascítico. Resultados: Observou-se que nos animais portadores de tumor houve uma redução significante do número de células tumorais e aumento do número de células inflamatórias, nos animais sem tumor observou-se influxo de células inflamatórias para a cavidade peritoneal. Conclusão: A solução proposta causa, in vivo, a diminuição do número de células stumorais e aumento do número de células inflamatórias no líquido ascítico.

DESCRITORES - Carcinoma de Ehrlich. Terapia combinada. Ascite.
\end{abstract}

\section{Introdução}

Em trabalho experimental anterior ${ }^{1}$ observamos que a solução composta por fenol, ácido acético, glicerina e água destilada ocasiona, in vitro, a destruição (inviabilidade) de células tumorais em suspensão do tumor ascitico de Ehrlich. Este efeito, imediato e dose dependente, decorria da destruição de estruturas citoplasmaticas e nucleares.

Com base em tais resultados, nos propusemos a estudar o efeito da infiltração dessa solução em camundongos portadores do tumor ascitico de Ehrlich, tendo em vista a necessidade de desenvolvimento de novas drogas e substâncias no tratamento da ascite de origem neoplásica. Estima-se que 10\% de todos os casos de ascite, são de origem neoplasica, sendo a maioria destas provenientes de tumores gastrointestinais e ovarianos.

Quanto ao tratamento da ascite neoplásica, as principais modalidades terapêuticas já consagradas são a paracentese, o uso de diuréticos e a quimioterapia sistêmica, a qual vem sendo progressivamente substituída pela via intraperitoneal; os resultados, infelizmente são de modo geral, pouco satisfatórios.

Neste sentido, diversas substâncias vem sendo estudadas (colóides radioativos, imunoestimuladores, inibidores de matriz de metaloproteases e novas drogas quimioterapicas), o que demonstra a importância no desenvolvimento de novas métodos no sentido de enfrentar o desafio no tratamento da ascite neoplasica.

Por outro lado, os dados da literatura demonstram a importância da relação entre o influxo de células inflamatórias e o crescimento tumoral $^{2,3}$, bem como a presença de infiltrado inflamatório (macrófagos e polimorfonucleraes) no estroma e na periferia de tecidos neoplasicos, como fator prognóstico, reforçando a dependência entre inflamação e crescimento tumoral.

Assim, frente a estes aspectos até aqui levantados, surgiu-nos a idéia de utilizar um modelo experimental de ascite tumoral, tumor de Ehrlich, para estudar os possíveis efeitos da solução esclerosante tanto nas células tumorais como nas inflamatórias.

Buscamos desta forma responder as seguintes perguntas: a) nos animais portadores de ascite neoplasica, a solução proposta reduz o número de células tumorais? b) injeção intraperitoneal da solução em animais sadios causa influxo de células inflamatórias?

Escolhemos como modelo o tumor ascitico de Ehrlich e como métrica a citologia do liquido ascitico, realizando a contagem de células inflamatórias e tumorais.

\section{Métodos}

Utilizou-se como modelo experimental o tumor ascítico de Ehrlich (TAE) em camundongos; a manutenção do tumor in vivo tem sido feita pela injeção intraperitoneal de $10^{7}$ células a cada sete dias em camundongos receptores.

A técnica para a manutenção tumoral, já descrita em trabalho anterior ${ }^{1}$, é a técnica clássica e amplamente utilizada.

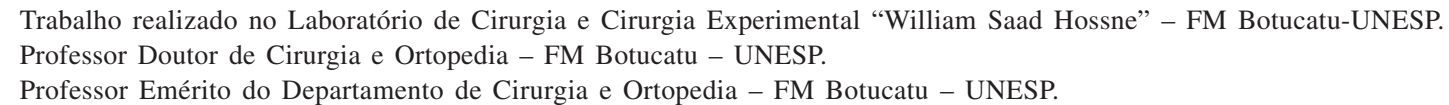


Foram utilizados 283 camundongos machos da linhagem Swiss, com quatro a seis semanas de vida, pesando entre vinte e trinta gramas, fornecidos pelo Biotério Central da Universidade Estadual Paulista (Unesp) Campus de Botucatu. Após o tratamento experimental foram alimentados com ração industrializada; no dia do tratamento experimental, os animais foram submetidos a jejum de seis horas, recebendo água ad libitum, permanecendo depois em caixas metálicas (dez animais em cada uma); a temperatura foi mantida entre $20^{\circ} \mathrm{C}$ a $25^{\circ} \mathrm{C}$, a umidade relativa variável entre $40 \%$ a $60 \%$ e o tempo de exposição à luz foi de 12 horas.

A solução testada é composta de fenol (0,6 g), ácido acético (0,6 g), glicerina ( $1,2 \mathrm{~g})$ e água bidestilada $(28,0 \mathrm{ml})$, preparada no Laboratório de Cirurgia Experimental do Departamento de Cirurgia e Ortopedia (Fac. Med. Botucatu).

A partir do líquido ascítico de cada animal sacrificado, foi realizada a contagem total e diferencial de células (células tumorais, polimorfonucleares e mononucleares). A contagem total foi feita em câmara de Neubauer e a contagem diferencial (contagem de cem células) após processamento da suspensão peritoneal em citocentrífuga e coloração pelo método de Giemsa.

\section{Protocolo 1}

Este protocolo foi delineado com o objetivo de verificar o efeito in vivo da solução em animais com tumor; como métrica, utilizou-se a celularidade presente no líquido ascítico.

Foram criados oito grupos experimentais com vinte animais em cada grupo. A quantidade de suspensão tumoral injetada foi de $10^{4}$ células $/ \mathrm{ml}$, o volume da solução teste (S.T.) foi de $0,25 \mathrm{ml}, 0,10 \mathrm{ml}$ ou $0,05 \mathrm{ml}$ e o de salina (S.S.) foi de 0,25 $\mathrm{ml}$; em todos os casos, a injeção foi feita três dias após a inoculação da suspensão tumoral. O sacrifício ocorreu após três e seis dias da injeção das soluções (seis e nove dias da inoculação tumoral). Para a contagem global e de células tumorais, considerou-se o grupo de vinte animais; para a contagem de células inflamatórias, utilizaram-se dez animais por grupo.

\section{Protocolo 2}

Com a finalidade de avaliar os efeitos da solução teste em animais não portadores do tumor de Ehrlich (sadios), foram criados 8 grupos experimentais, com cinco animais em cada, e procedeu-se a injeção de $0,25 \mathrm{ml}, 0,10 \mathrm{ml}$ e $0,05 \mathrm{ml}$ da solução teste e $0,25 \mathrm{ml}$ de solução salina, realizouse o sacrifício três e seis dias após a injeção da solução, sendo determinada a contagem global das células nas amostras do líquido ascítico.

Foi realizada análise de variância da contagem total e diferencial das células (tumorais e inflamatórias) no líquido ascítico, considerando quatro tratamentos e dois momentos. A comparação de médias foi feita pelo teste de Tukey.

A mortalidade, nos diferentes grupos, foi analisada pela frequiência relativa (porcentagem).

Adotou-se, como nível de significância, o índice igual a ou menor que 5\% $(p<0,05)$. Nas tabelas, as médias seguidas de mesma letra maiúscula na vertical e minúscula na horizontal não diferem entre si, pelo teste de Tukey, ao nível de $5 \%$ de significância.

\section{Resultados}

\section{Protocolo 1 - Animais com tumor}

1.1 - Mortalidade nos grupos (Tabela 1)

1.2 - Contagem total de células (tabelas 2 e 3 e figura 1)

\section{3 - Contagem diferencial}

A análise diferencial foi realizada contando-se o número de células tumorais e de células inflamatórias (polimorfonucleares e mononucleares).

\subsection{1- Células Tumorais}

\subsection{2 - Contagem de Células}

Inflamatórias (Polimorfonucleares e mononucleares)

As Figuras 5 a 8 (esfregaços do líquido ascítico) ilustram nitidamente os efeitos da solução teste em animais com tumor.

A Figura 5 refere-se ao esfregaço do líquido ascítico de camundongo tratado com $0,25 \mathrm{ml}$ de S.S. e sacrificado após seis dias de tratamento ; pode-se notar que a quase totalidade de células é de origem tumoral (caracterizadas pelo citoplasma reduzido e o núcleo volumoso), sendo escassas as células inflamatórias.

A Figura 6 corresponde ao esfregaço do líquido ascítico de camundongo pertencente ao grupo tratado com $0,05 \mathrm{ml}$ de S.T. e sacrificado após seis dias de tratamento; pode-se notar que houve nítida redução da quantidade de células tumorais (T) e aumento de células inflamatórias: polimorfonucleares $(\mathrm{P})$ e mononucleares (M).

A Figura 7 refere-se ao esfregaço do líquido ascítico de camundongo tratado com $0,10 \mathrm{ml}$ de S.T. e sacrifícado após seis dias de evolução; nota-se a presença de intenso infiltrado inflamatório com predomínio de mononucleares e a escassez de células tumorais. Quando se compara com a Figura 1 (controle), a diferença fica bem evidente, demonstrando o efeito da S.T.

A Figura 8 corresponde ao esfregaço do líquido ascítico de camundongo tratado com $0,25 \mathrm{ml}$ de $\mathrm{S}$.T. e sacrificado após seis dias de tratamento; pode-se notar, também, o predomínio de células inflamatórias, mononucleares, em detrimento da pequena quantidade de células tumorais.

Vale salientar, com relação aos mononucleares, que em todas as lâminas estudadas a quase totalidade das células era composta de macrófagos, com muito poucos linfócitos.

Protocolo 2 - Animais sem tumor. Celularidade do líquido ascítico (contagem total)

\section{1 - Mortalidade nos grupos} (Tabela 10)

2.2 - Contagem total (Tabelas 11 e 12 e Figura 9) 
TABELA 1 - Mortalidade (\%) nos grupos, no $3^{0}$ e $6^{0}$ dia, após o tratamento com S.S. ou S.T.. Protocolo 1

\begin{tabular}{ccc}
\hline Grupo & $\mathbf{3}^{\mathbf{0}} \mathbf{\text { dia }}$ & $\mathbf{6}^{\mathbf{0}} \mathbf{\text { dia }}$ \\
\hline T.A.E.+S.S. & $0 \%$ & $30 \%$ \\
T.A.E.+ 0,25 ml S.T. & $60 \%$ & $55 \%$ \\
T.A.E.+ 0,10 ml S.T. & $10 \%$ & $10 \%$ \\
T.A.E.+ 0,05 ml S.T. & $0 \%$ & $20 \%$ \\
\hline
\end{tabular}

TABELA 2 - Análise de variância. Número total de células no líquido ascítico em animais com tumor. Protocolo 1

\begin{tabular}{cccc}
\hline Causa da variação & G.L. & Q.M. & F \\
\hline Tratamento(T) & 3 & 4,0 & $8,6^{* *}$ \\
Momentos (M) & 1 & 1,4 & $3,0 \mathrm{~ns}$ \\
Interação(T x M) & 3 & 1,3 & $2,8 * *$ \\
Resíduo & 115 & 0,4 & \\
\hline
\end{tabular}

TABELA 3 - Número total de células $\left(10^{6}\right.$ cels. $\left./ \mathrm{ml}\right)$ no líquido ascítico de camundongos portadores de tumor de Ehrlich após 3 e 6 dias de tratamento com S.S. ou S.T. Média, desvio padrão e $\mathrm{n}^{\circ}$ de animais. Protocolo 1 .

\begin{tabular}{|c|c|c|c|c|}
\hline \multirow[b]{2}{*}{ Tratamentos } & \multicolumn{4}{|c|}{ Momentos } \\
\hline & $3^{\circ}$ dia & & $6^{\circ}$ dia & \\
\hline \multirow[t]{2}{*}{ T.A.E. + 0,25 ml S.S. } & $\begin{array}{r}5,8 \pm 3,3 \\
(\mathrm{n}=20)\end{array}$ & $\mathbf{A B ~ b}$ & $\begin{array}{c}9,6 \pm 4,1 \\
(\mathrm{n}=14)\end{array}$ & $\mathbf{A a}$ \\
\hline & $9,0 \pm 4,4$ & $\mathbf{A b}$ & $11,0 \pm 5,6$ & A $\mathbf{a}$ \\
\hline \multirow[t]{2}{*}{ T.A.E. $+0,25 \mathrm{ml}$ S.T. } & $(\mathrm{n}=8)$ & & $(\mathrm{n}=9)$ & \\
\hline & $4,6 \pm 3,9$ & $\mathbf{B} \mathbf{a}$ & $5,4 \pm 3,3$ & A a \\
\hline T.A.E. + 0,10 ml S.T. & $\begin{array}{c}(n=18) \\
59+27\end{array}$ & $A B \mathbf{a}$ & $\begin{array}{c}(n=18) \\
47+27\end{array}$ & $\mathbf{B ~ b}$ \\
\hline T.A.E. + 0,05 ml S.T. & $(n=20)$ & & $(n=16)$ & \\
\hline
\end{tabular}

Médias seguidas de mesma letra maiúscula na vertical e minúscula na horizontal não diferem entre si, pelo teste de Tukey, ao nível de 5\% de significância.

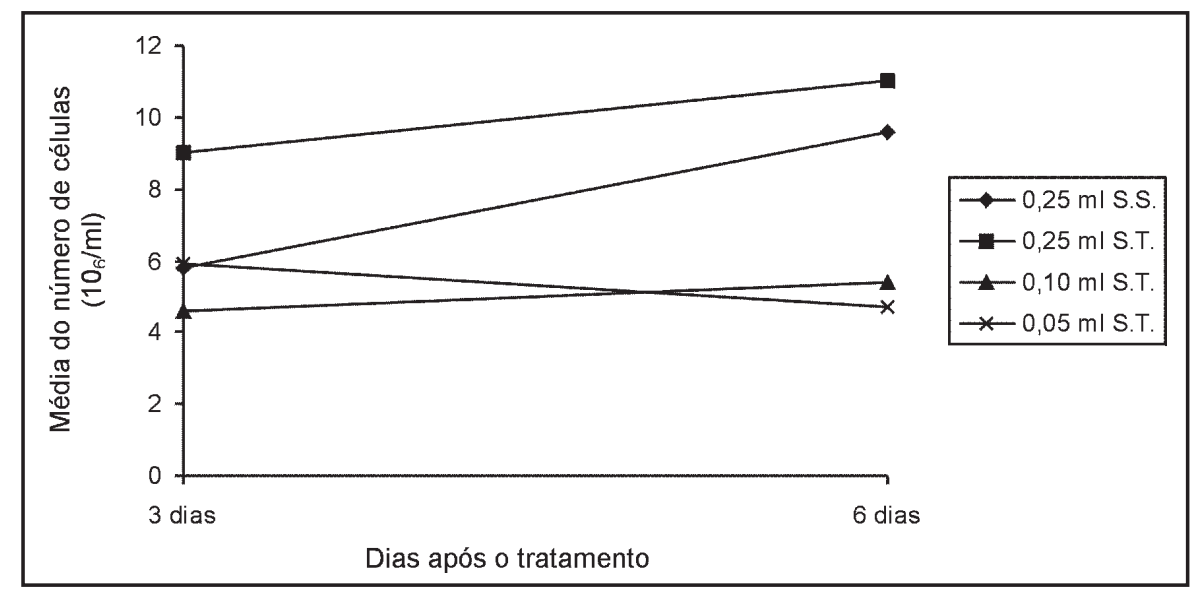

FIGURA 1 - Média do número total de células no líquido ascítico de camundongos portadores de tumor de Ehrlich após 3 e 6 dias de tratamento com S.S. ou S.T. Protocolo 1. 
TABELA 4 - Análise de variância. Número de células tumorais no líquido ascítico. Protocolo 1.

\begin{tabular}{cccc}
\hline Causa da Variação & G.L. & Q.M. & F \\
\hline Tratamentos (T) & 3 & 64,1 & $59,1 * *$ \\
Momentos (M) & 1 & 50,4 & $46,2 * *$ \\
Interação (T x M) & 3 & 3,2 & $2,9 * *$ \\
Resíduo & 85 & 1,0 & \\
\hline
\end{tabular}

Coeficiente de Variação $=16,3 \%$

TABELA 5 - Número de células tumorais (em cem células) no líquido ascítico de camundongos portadores do tumor de Ehrlich após 3 e 6 dias de tratamento com S.S ou S.T.- Média, desvio padrão e n ${ }^{\circ}$ de animais. Protocolo 1

\begin{tabular}{|c|c|c|c|c|}
\hline \multirow[b]{2}{*}{ Tratamentos } & \multicolumn{4}{|c|}{ Momentos } \\
\hline & $3^{\circ}$ dia & & $6^{0}$ dia & \\
\hline \multirow[t]{2}{*}{ T.A.E. + 0,25 ml S.S. } & $\begin{array}{c}55,8 \pm 13,1 \\
(\mathrm{n}=20)\end{array}$ & $\mathbf{A b}$ & $\begin{array}{c}82,6 \pm 17,3 \\
(\mathrm{n}=14)\end{array}$ & Aa \\
\hline & $11,0 \pm 10,0$ & $\mathbf{C b}$ & $32,0 \pm 10,4$ & $\mathbf{C a}$ \\
\hline \multirow[t]{2}{*}{ T.A.E. $+0,25 \mathrm{ml}$ S.T. } & $(n=8)$ & & $(n=9)$ & \\
\hline & $22,3 \pm 9,5$ & $\mathbf{B} \mathbf{a}$ & $26,4 \pm 8,7$ & $\mathbf{C a}$ \\
\hline T.A.E. + 0,10 ml S.T. & $\begin{array}{c}(\mathrm{n}=18) \\
29,5 \pm 10,8\end{array}$ & $\mathbf{B} \mathbf{b}$ & $\begin{array}{c}(\mathrm{n}=18) \\
51,9 \pm 16,6\end{array}$ & $\mathbf{B} \mathbf{a}$ \\
\hline T.A.E. + 0,05 ml S.T. & $(n=20)$ & & $(\mathrm{n}=16)$ & \\
\hline
\end{tabular}

Médias seguidas de mesma letra maiúscula na vertical e minúscula na horizontal não diferem entre si, pelo teste de Tukey, ao nível de 5\% de significância.

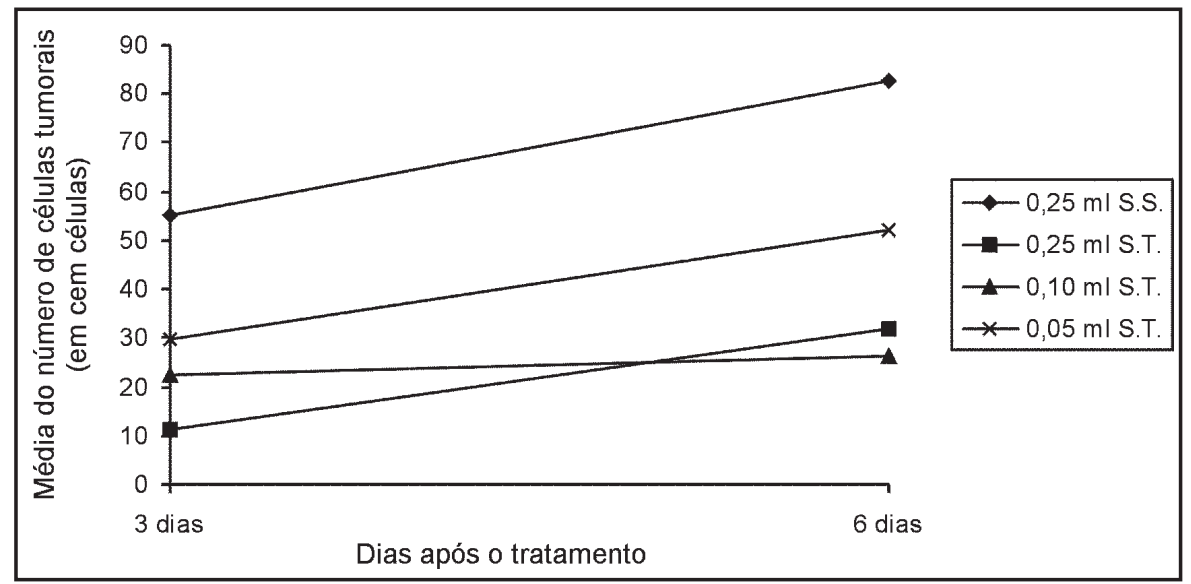

FIGURA 2 - Número de células tumorais (em cem células) no líquido ascitico de camundongos portadores do tumor de Ehrlich após 3 e 6 dias de tratamento com S.S. ou S.T. (valores médios). Protocolo 1

TABELA 6 - Análise de variância. Número de polimorfonucleares no liquido ascítico. Protocolo 3

\begin{tabular}{cccc}
\hline Causa da Variação & G.L. & Q.M. & F \\
\hline Tratamentos (T) & 3 & 4,2 & $4,3 * *$ \\
Momentos (M) & 1 & 198,6 & $199,7 * *$ \\
Interação (Mx T) & 3 & 2,5 & $2,5 \mathrm{~ns}$ \\
Resíduo & 47 & 0,9 & \\
\hline
\end{tabular}


TABELA 7 - Número de polimorfonucleares (em cem células) no líquido ascítico de camundongos portadores de tumor de Ehrlich após 3 e 6 dias de tratamento com S.S. ou S.T. - Média , desvio padrão e $\mathrm{n}^{\circ}$ de animais. Protocolo 1

\begin{tabular}{cccc}
\hline \multirow{2}{*}{ Tratamentos } & \multicolumn{2}{c}{ Momentos } & Média dos \\
& $\mathbf{3}^{\text { dia }}$ & $\mathbf{6}^{\mathbf{0}} \mathbf{\text { dia }}$ & Tratamentos \\
\hline T.A.E. + 0,25 ml S.S. & $28,1 \pm 8,4,1$ & $2,6 \pm 3,3$ & 15,3 \\
& $(\mathrm{n}=10)$ & $(\mathrm{n}=10)$ & \\
T.A.E.+ 0,25 ml S.T. & $44,0 \pm 16,9$ & $4,8 \pm 8,6$ & 24,4 \\
& $(\mathrm{n}=2)$ & $(\mathrm{n}=5)$ & \\
T.A.E. + 0,10 ml S.T. & $34,0 \pm 6,3$ & $0,4 \pm 0,8$ & 17,2 \\
& $(\mathrm{n}=10)$ & $(\mathrm{n}=5)$ & \\
T.A.E. + 0,05 ml S.T. & $36,4 \pm 9,8$ & $9,7 \pm 7,6$ & 23,0 \\
& $(\mathrm{n}=10)$ & $(\mathrm{n}=8)$ & \\
Média dos Momentos & 35,6 & 4,3 & \\
\hline
\end{tabular}

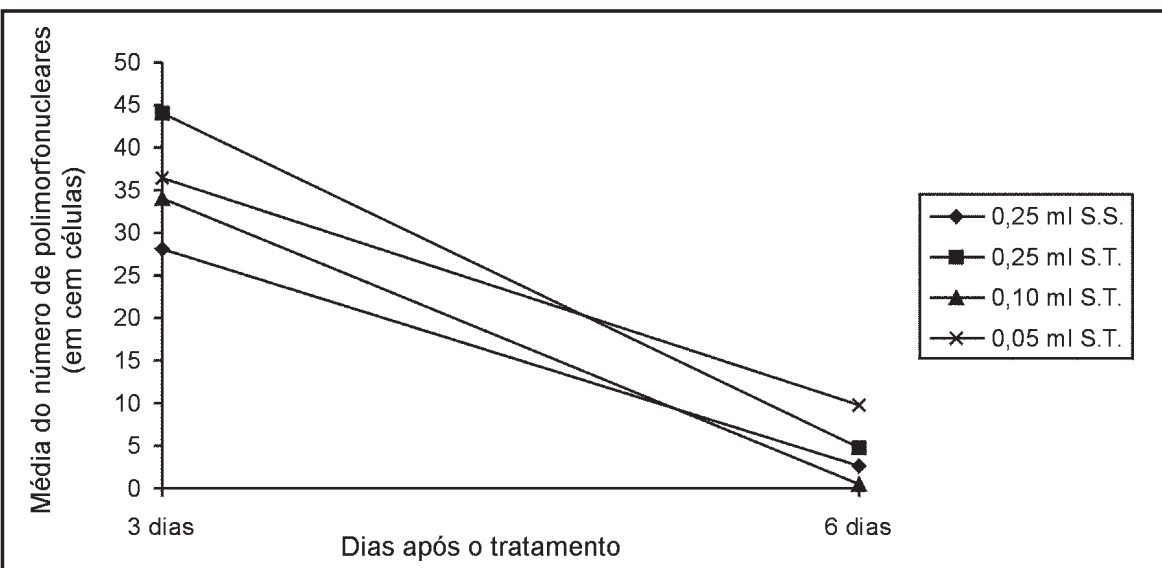

FIGURA 3 - Número de polimorfonucleares (em cem células) no líquido ascítico de camundongos portadores de tumor de Ehrlich após 3 e 6 dias de tratamento com S.S. ou S.T. (valores médios). Protocolo 1

TABELA 8 - Análise de variância. Número de mononucleares no líquido ascítico. Protocolo

\begin{tabular}{cccc}
\hline Causa da Variação & G.L. & Q.M. & F \\
\hline Tratamentos $(\mathbf{T})$ & 3 & 55,1 & $89,2 * *$ \\
Momentos $(\mathbf{M})$ & 1 & 2,8 & $4,5 * *$ \\
Interação $(\mathbf{T} \times \mathbf{M})$ & 3 & 4,6 & $7,5 * *$ \\
Resíduo & 47 & 0,6 & \\
\hline
\end{tabular}

Coeficiente de Variação $=14,2 \%$

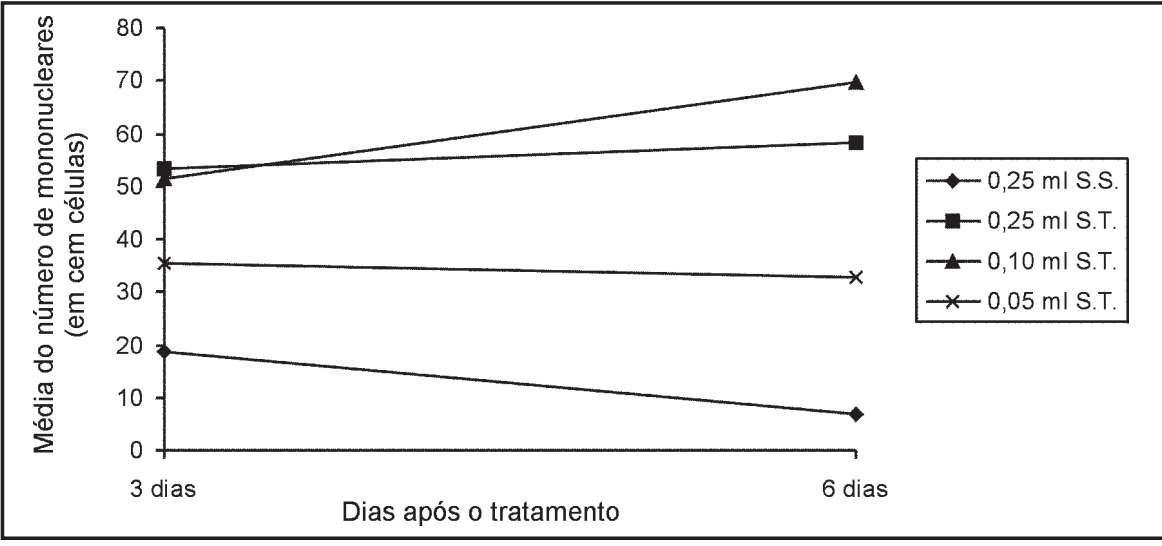

FIGURA 4 - Número de mononucleares (em cem células) no liquido ascítico de camundongos portadores de tumor de Ehrlich após 3 e 6 dias de tratamento com S.S. ou S.T. (valores médios). Protocolo 1. 
TABELA 9 - Número de mononucleares (em cem células) no líquido ascítico de camundongos portadores de tumor de Ehrlich após 3 e 6 dias de tratamento com S.S. ou S.T. - Média, desvio padrão e $\mathrm{n}^{\circ}$ de animais. Protocolo 1

\begin{tabular}{|c|c|c|c|c|}
\hline \multirow[b]{2}{*}{ Tratamentos } & \multicolumn{4}{|c|}{ Momentos } \\
\hline & $3^{\circ}$ dia & & $6^{0}$ dia & \\
\hline \multirow{3}{*}{ T.A.E. + Salina } & $18,5 \pm 6,5$ & $\mathbf{C a}$ & $7,0 \pm 2,7$ & $\mathbf{C b}$ \\
\hline & $(n=10)$ & & $(n=10)$ & \\
\hline & $53,5 \pm 16,2$ & $\mathbf{A B} \mathbf{a}$ & $58,2 \pm 12,8$ & A a \\
\hline \multirow[t]{2}{*}{ T.A.E. + 0,25 ml S.T. } & $(n=2)$ & & $(n=5)$ & \\
\hline & $51,6 \pm 6,6$ & $\mathbf{A b}$ & $69,6 \pm 5,3$ & A $\mathbf{a}$ \\
\hline \multirow[t]{2}{*}{ T.A.E. $+0,10 \mathrm{ml}$ S.T. } & $(\mathrm{n}=5)$ & & $(\mathrm{n}=5)$ & \\
\hline & $35,5 \pm 7,7$ & $\mathbf{B} \mathbf{a}$ & $32,6 \pm 12,4$ & $\mathbf{B} \mathbf{a}$ \\
\hline T.A.E. + 0,05 ml S.T. & $(n=10)$ & & $(\mathrm{n}=8)$ & \\
\hline
\end{tabular}

Médias seguidas da mesma letra maiúscula na vertical e minúscula na horizontal não diferem entre si, pelo teste de Tukey, ao nível de 5\% de significância.

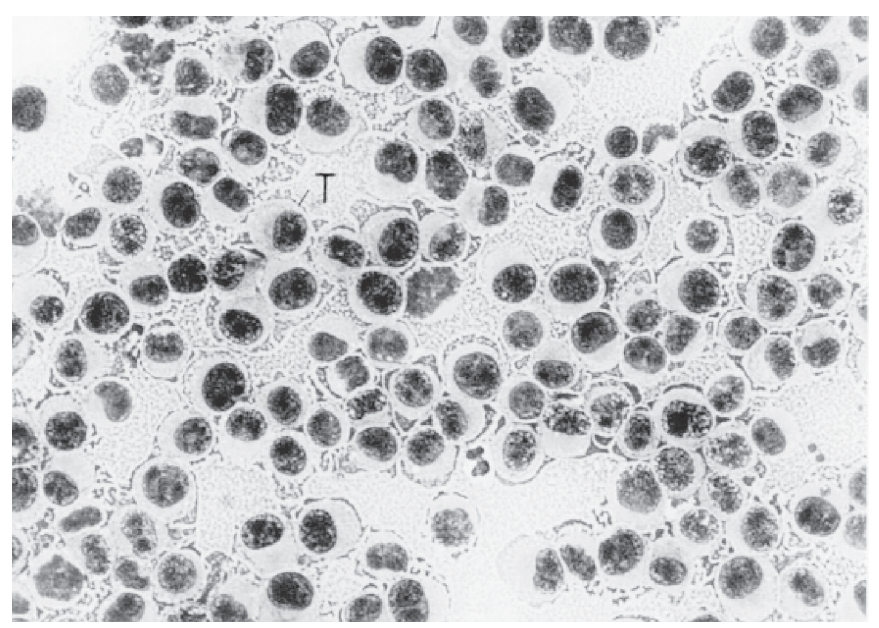

FIGURA 5 - Esfregaço do líquido ascítico de camundongo tratado com S.S., sacrifícado após 6 dias de tratamento. Notar que a quase totalidade é de células tumorais $(\mathrm{T})$, caracterizadas por citoplasma escasso, núcleo volumoso e a clara delimitação da membrana celular e a escassez de células inflamatórias. X400. Coloração Giemsa.

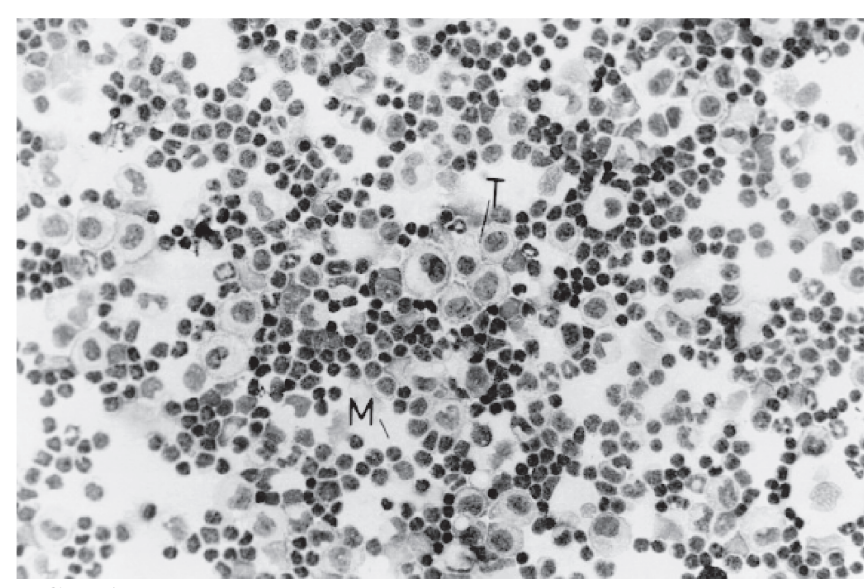

FIGURA 7 - Esfregaço do líquido ascítico de camundongo tratado com $0,10 \mathrm{ml} \mathrm{S.T.,} \mathrm{sacrifícado} \mathrm{após} 6$ dias de tratamento. Notar o intenso infiltrado inflamatório, com predomínio de mononucleares $(\mathrm{M})$ e a escassez de células tumorais( $\mathrm{T})$, com redução evidente em relação à Figura 9 (solução salina). X 200. Coloração Giemsa.

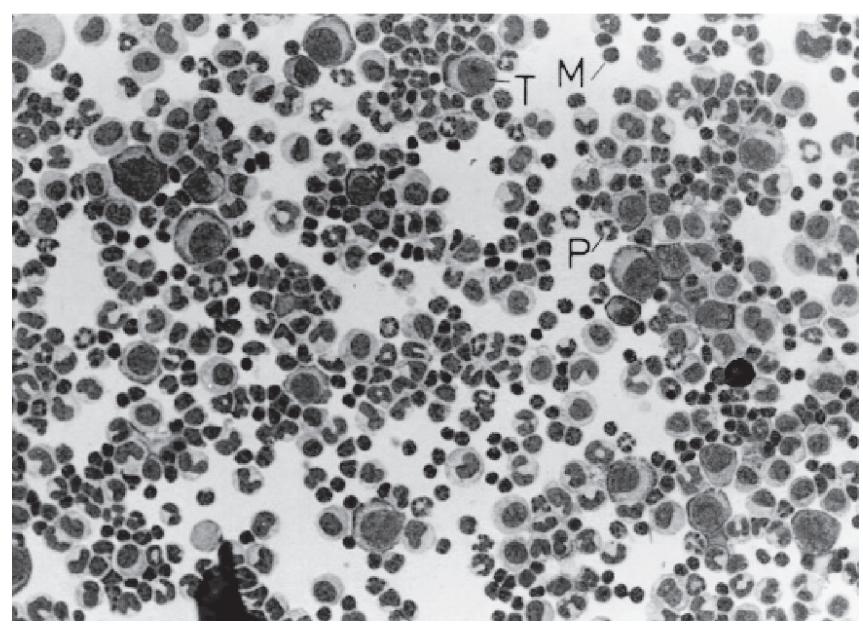

FIGURA 6 - Esfregaço do líquido ascítico de camundongo tratado com $0,05 \mathrm{ml} \mathrm{S}$.T., sacrifícado após 6 dias de tratamento. Notar aumento do número de células inflamatórias, mononucleares $(\mathrm{M})$ e polimorfonucleares (P), e a redução do número de células tumorais (T). X.200. Coloração Giemsa.

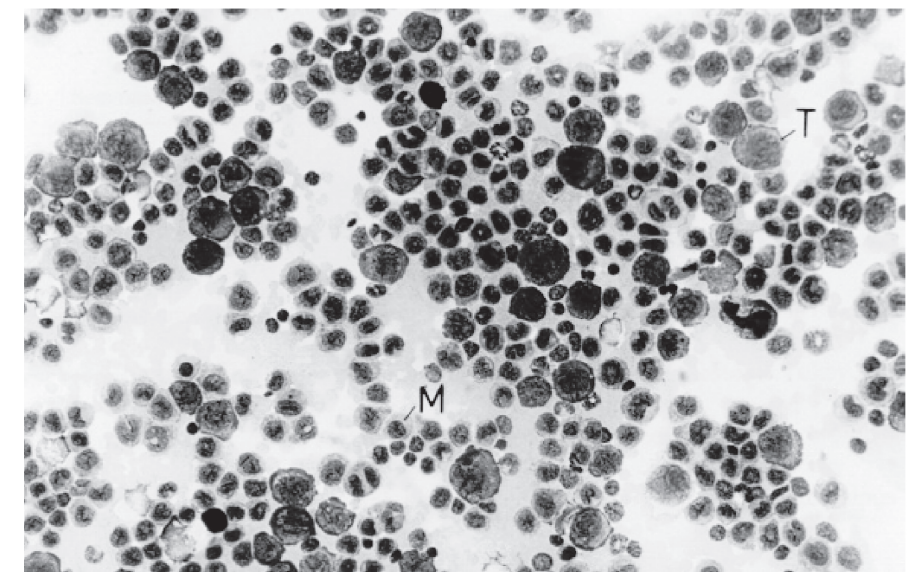

FIGURA 8 - Esfregaço do líquido ascítico de camundongo tratado com 0,25 ml S.T., sacrifícado após 6 dias de tratamento. Notar o predomínio de células inflamatórias, ás custas de mononucleares (M), e a evidente redução do número de células tumorais (T) em comparação à Figura 9 .X 300 Coloração Giemsa. 
TABELA 10 - Mortalidade (\%) nos grupos, no $3^{0}$ e $6^{0}$ dia após o tratamento. Protocolo 2

\begin{tabular}{ccc}
\hline Grupo & $\mathbf{3}^{\mathbf{0}} \mathbf{d i a}$ & $\mathbf{6}^{\mathbf{0}} \mathbf{d i a}$ \\
\hline Sem tumor + 0,25 ml S.S. & $0 \%$ & $0 \%$ \\
Sem tumor + 0,25 ml S.T. & $60 \%$ & $60 \%$ \\
Sem tumor + 0,10 ml S.T. & $20 \%$ & $20 \%$ \\
Sem tumor + 0,05 ml S.T. & $0 \%$ & $0 \%$ \\
\hline
\end{tabular}

TABELA 11 - Análise de variância. Número total de células no líquido ascítico em animais sem tumor. Protocolo 2.

\begin{tabular}{cccc}
\hline Causa da Variação & G.L. & Q.M. & F \\
\hline Tratamentos (T) & 3 & 0,4 & $6,2 * *$ \\
Momentos (M) & 1 & 0,1 & $2,5 \mathrm{~ns}$ \\
Interação $(\mathbf{T}$ x M) & 3 & 0,4 & $7,7 * *$ \\
Resíduo & 24 & 0,06 & \\
\hline
\end{tabular}

Coeficiente de Variação $=12,5 \%$

TABELA 12 - Número total de células $\left(10^{4}\right.$ cels. $\left./ \mathrm{ml}\right)$ no líquido ascítico de camundongos sem tumor de Ehrlich após 3 e 6 dias de tratamento com S.T.Média, desvio padrão e n ${ }^{\circ}$ de animais. Protocolo 2

\begin{tabular}{|c|c|c|c|c|}
\hline \multirow[t]{2}{*}{ Tratamentos } & \multicolumn{4}{|c|}{ Momentos } \\
\hline & $3^{\circ}$ dia & & $6^{0}$ dia & \\
\hline Sem Tumor + Salina & $\begin{array}{c}3,7 \pm 0,7 \\
(\mathrm{n}=5)\end{array}$ & $\mathrm{ACa}$ & $\begin{array}{c}4,3 \pm 1,1 \\
(n=5)\end{array}$ & $\overline{\mathrm{AB} \mathbf{a}}$ \\
\hline Sem Tumor + 0,25 ml S.T. & $\begin{array}{c}2,6 \pm 0,4 \\
(\mathrm{n}=2)\end{array}$ & $\mathrm{BCb}$ & $\begin{array}{c}6,7 \pm 0,5 \\
(n=2)\end{array}$ & $\bar{A} \mathbf{a}$ \\
\hline Sem Tumor + 0,10 ml S.T. & $\begin{array}{c}5,0 \pm 0,9 \\
(\mathrm{n}=4) \\
2,0 \pm 1,1\end{array}$ & $\begin{array}{l}\mathbf{A a} \\
\mathbf{B} \mathbf{a}\end{array}$ & $\begin{array}{c}3,0 \pm 1,1 \\
(n=4) \\
3,1 \pm 0,9\end{array}$ & $\begin{array}{l}\mathbf{B ~ b} \\
\mathbf{B} \mathbf{a}\end{array}$ \\
\hline Sem Tumor + 0,05 ml S.T. & $(n=5)$ & & $(\mathrm{n}=5)$ & \\
\hline
\end{tabular}

Médias seguidas da mesma letra maiúscula na vertical e minúscula na horizontal não diferem entre si, pelo teste de Tukey, ao nível de 5\% de significância.

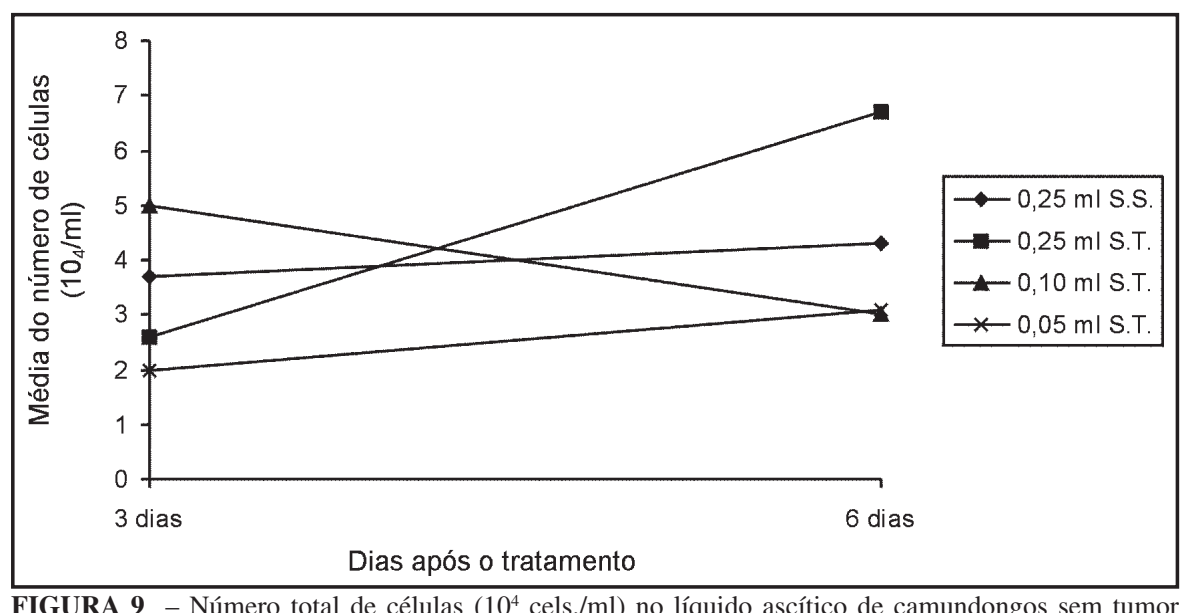

FIGURA 9 - Número total de células $\left(10^{4}\right.$ cels. $\left./ \mathrm{ml}\right)$ no líquido ascítico de camundongos sem tumor de Ehrlich após 3 e 6 dias de tratamento com S.S ou S.T. (Valores médios). Protocolo 2. 


\section{Discussão}

A solução testada é composta de fenol $(0,6 \mathrm{~g})$, ácido acético $(0,6 \mathrm{~g})$, glicerina $(1,2 \mathrm{~g})$ e água bidestilada $(28 \mathrm{ml})$. O fenol é uma substância que tem poder bacteriostático (solução a $0,02 \%$ a $1 \%$ ), bactericida, germicida e histotóxico. O ácido acético glacial tem efeito bactericida a $5 \%$, e bacteriostático a $1 \%$, além de apresentar capacidade cáustica e antifúngica ${ }^{4}$.

A glicerina é um álcool triidroxilado, amplamente empregado como veículo para muitas drogas aplicadas na pele, quando administrada por via oral, pode ser usada no tratamento do edema cerebral e na diminuição da tensão ocular no glaucoma ${ }^{4}$.

Esses dados evidenciam efeito bactericida do fenol e do ácido acético, indicando a possibilidade de atuação lítica das duas substâncias, agora empregadas em associação; esta solução, rotulada como "esclerosante" foi utilizada empiricamente, para o tratamento da hiperplasia prostática, no início deste século e nas décadas de 1960 e $19700^{5}$.

Em nosso meio, Camara ${ }^{5}$ estudou os efeitos da injeção da solução na próstata de cães, tendo observado ocorrência de necrose do tecido, seguida de fibrose.

Revendo a literatura, não encontramos referências ao uso dessa solução no tumor ascítico de Ehrlich ou na ascite neoplásica, justificando-se, assim a nosso ver, a oportunidade da investigação proposta em nosso trabalho.

Tendo em vista os resultados obtidos no trabalho anterior (in vitro), optamos por utilizar as doses de $0,25 \mathrm{ml}$, $0,10 \mathrm{ml} \mathrm{e} 0,05 \mathrm{ml}$ da solução teste.

A eficácia de uma droga antitumoral é, em geral, avaliada pela sua capacidade de reduzir a quantidade de células tumorais; contudo, ressalta-se a importância da relação da resposta imune do hospedeiro frente ao tumor, refletida pela presença de células inflamatórias no local da neoplasia. Associado a isto, vale enfatizar que o tumor ascítico de Ehrlich inibe o influxo das células inflamatórias para a cavidade peritoneal, justificando-se asssim, a contagem diferencial das células.

Quando avaliamos as características dos grupos como um todo, notamos que houve grande aumento do número de células tumorais, do $3^{\circ}$ para o $6^{\circ}$ dia, no grupo controle $(0,25 \mathrm{ml}$ de S.S.); aliás, o número de células tumorais foi significa- tivamente maior no grupo-controle do que nos grupos tratados, em todos os momentos. Na avaliação do grupo controle, nos dois momentos, notamos aumento estatisticamente significante no número das células tumorais; o mesmo acontecendo nos grupos de $0,25 \mathrm{ml}$ e de $0,05 \mathrm{ml} \mathrm{de}$ S.T., fato não ocorrido no grupo de 0,10 $\mathrm{ml}$ de S.T. em que não houve diferença entre os dois momentos

Isto sugere que a droga inibiu o crescimento tumoral em todos os momentos, sendo a ação mais efetiva no primeiro momento, na dose de $0,25 \mathrm{ml}$ de S.T. e, no segundo momento, na dose de $0,10 \mathrm{ml}$ de S.T.

Esta inibição, com redução do crescimento tumoral, também foi observada por alguns autores que utilizaram a via intraperitoneal para teste de outras drogas: com a dopamina ${ }^{6}$; com o fator de necrose tumoral e interleucina 2 combinados com administração oral de indometacina ${ }^{7}, \mathrm{com}$ antagonista do fator ativador de plaquetas $^{8}$, com a cisplatina ${ }^{9}$, com hipertemia associada à cisplatina ${ }^{10}$; com Plumbago rosea $^{11}$ (planta medicinal indiana); com antígenos capsulares de Klebsiella ${ }^{12}$; e com a deoxiadenosina ${ }^{13}$.

Outros autores obtiveram resultados semelhantes, empregando outras drogas, utilizando, porém, outras vias: via oral, com a indometacina ${ }^{7}$, com kifirir ${ }^{14}$ (produto do leite fermentado do Cáucaso); via subcutânea: com a estriquinopentamina ${ }^{15}$, e com a cisteína ${ }^{16}$; via intravenosa: com o 5-fluorouracil ${ }^{17}$, utilizando o azul de metileno ${ }^{18}$, com a vitamina $\mathrm{A}^{19}$, com a lisozima $^{20}$, com o haloperidol ${ }^{21}$, com a bleomicina e dolomite ${ }^{22}$, com a cefarantina e a adriamicina ${ }^{23}$, com o uso de dipiridamo$\mathrm{le}^{24}$, com a cisplatina ${ }^{25}$ e com a carboplatina associada a hipertermia ${ }^{26}$.

Ao avaliarmos a contagem de polimorfonucleares e mononucleares (macrófagos, em sua quase totalidade) em conjunto, notamos que, no primeiro momento, em todos os grupos tratados com S.T. o número de células inflamatórias foi superior ao encontrado no grupo-controle. Nos grupos tratados com S.T. houve elevação inicial do número de polimorfonucleares, ocorrendo diminuição gradativa para o segundo momento; já o número de mononucleares também se iniciou com valores bem mais altos em relação ao grupocontrole apresentando, ainda, tendência de aumento no segundo momento ( $\left.6^{\circ} \mathrm{dia}\right)$, havendo diferença significante nos dois momentos, em relação ao controle.
Isto sugere que, inicialmente, os polimorfonucleares atuam conjuntamente com os mononucleares ( $1^{\circ}$ momento); a seguir, há diminuição de polimorfonucleares e tendência ao aumento de mononucleares, que seriam responsáveis pela inibição tardia (posterior) no crescimento tumoral, como sugerem os resultados da análise estatística.

O estudo das células inflamatórias nos processos tumorais, como enfatiza Fecchio $^{8}$, tem grande importância, dada a relação entre o crescimento tumoral e o infiltrado inflamatório de polimorfonucleares e, principalmente, de mononucleares. O resultado por nós obtido justifica o prosseguimento da pesquisa no sentido de se avaliar o estado funcional dos macrófagos.

Por outro lado, Fecchio ${ }^{8}$ chama a atenção para o fato de que muitos pesquisadores demonstram a ocorrência de ação antiinflamatória por parte das células neoplásicas, o que ressalta a importância dos nossos achados.

Frente a estes achados, tornou-se importante avaliar os eventuais efeitos da solução teste sobre o influxo de células inflamatórias (polimorfonucleares e mononucleares) para a cavidade peritoneal, em animais livres de tumor; neste sentido foi criado o Protocolo 2.

A análise de variância demonstra que há diferença significante entre tratamentos e interação tratamento/momento.

O grupo controle (S.S.) apresentou no $3^{\circ}$ dia maior quantidade de células que os grupos de $0,05 \mathrm{ml}$ e de $0,25 \mathrm{ml}$ de $\mathrm{S}$.T. e inferior ao grupo de $0,10 \mathrm{ml}$ de S.T.; no segundo momento, continuou superior a do grupo de 0,05 ml de S.T. e, agora, também à do grupo de $0,10 \mathrm{ml}$ de $\mathrm{S}$.T., porém inferior à do grupo de $0,25 \mathrm{ml}$ de $\mathrm{S}$.T.

Há diferença entre os grupos tratados, esta diferença ocorre no primeiro momento ( $3^{\circ} \mathrm{dia}$ ) no grupo de $0,10 \mathrm{ml}$ de S.T. e, no segundo momento ( $\left.6^{\circ} \mathrm{dia}\right)$, no grupo de $0,25 \mathrm{ml}$ de $\mathrm{S}$.T.. Isto sugere que, inicialmente, a reação do peritônio à droga é mais intensa no grupo de $0,10 \mathrm{de} \mathrm{ml}$ S.T. e, com o passar dos dias, torna-se mais intensa no grupo que recebeu maior dose ( $0,25 \mathrm{mlde}$ S.T).

Os resultados indicam, pois, que a solução-teste estimula o influxo de células para a cavidade peritoneal. 


\section{Conclusão}

A partir das observações experimentais podemos concluir que a solução testada no modelo experimental de tumor ascítico de Ehrlich reduz o número de células tumorais e eleva do número de células inflamatórias em suspensão no líquido ascítico e que nos animais sem tumor determina o influxo de células em suspensão na cavidade peritoneal.

\section{Referências}

1. Saad-Hossne R. Efeitos da solução aquosa de fenol, ácido acético e glicerina sobre a celularidade no líquido ascítico do tumor de Ehrlich em camundongo [Dissertação Mestrado]. Universidade Estadual Paulista Faculdade de Medicina de Botucatu; 1997.

2. Evans R. Macrophage in syngeneic animal tumors. Transplantation 1972;14:468-73.

3. Talmadge JE, Keu M, Filder IJ. Macrophage content metastatic and non metastatic roden neoplasms. J Immunol 1981;126:2245-8.

4. Goodman LS, Gilman AG. As bases farmacológicas da terapêutica. 7 ed. Rio de Janeiro: Guanabara; 1987.

5. Camara FR. Injeção prostática de solução esclerosante: estudo experimental no cão. [Tese - Doutorado]. Universidade Estadua Paulista - Faculdade de Medicina de Botucatu;1973.

6. Dasgupta PS, Lahiri T. Antitumor effect of i.p. dopamine in mice bearing Ehrlich ascites carcinoma. J Cancer Res Clin Oncol 1987;113:363-8.

7. Lala PK, Parhar RS, Singh P, Lala PK. Cure of murine Ehrlich ascites tumors with chronic oral indomethacin therapy combined with intraperitoneal administration of LAK cells and IL-2. Cancer Lett 1990;51:27-35.
8. Fecchio D, Russo M, Sirois P, Braquet $\mathrm{P}$ Jancar S. Inhibition of Ehrlich ascites tumo in vivo by PAF antagonist. Int Immunopharmacol 1990;12:57-65.

9. Landrito JE, Yoshiga K, Sakurai K, Takada K. Effects of intralesional injection of cisplatin dissolved in urografin and lipiodol on Ehrlich ascites tumor and normal tissues of CD-1 mice.Cancer Chemother Pharmacol 1994;34:323-30.

10. Chen Z, Peng D, Tan J. The inhibitory effect of intraperitoneal hyperthermic and hipotonic chemoterapy on ascites cancer cells in mice[ Abstract]. Hua Hsi I Ko Ta Hsueh Pao 1995;26:101-4.

11. Devi PV, Solomon FE, Dsarada AC. In vivo tumor inhibitory effects of an Indian medicinal plant, Plumbago rosea on experimental mouse tumor. Indian $\mathrm{J}$ Exp Biol 1994;32:523-8.

12. Choy YM, Tsang SF, Kong SK, Leung KN, Parolis H, Lee CY, Fung KP. K1 and K3 capsular antigens of Klebsiella induce tumor necrosis factor activities. Life Sci 1996;58:153-8.

13. Svendsen KR, Overgaard-Hansen K, Frederiksen S, Spang-Thomsen M. The effect of 3-deoxuadenosine on oxide on growth in vitro and in vivo on Ehrlich ascites tumor and on a human squamous lung cell carcinoma xenograft in nude mice. Cancer Invest 1996;14:19-24.

14. Kubo M, Odani T, Nakamura S, Tokumaru S, Matsuda H. Pharmacological study on Kifir, a fermented milk product in Caucasus, on antitumor activity [Abstract]. Yakugaku Zasshi 1992;112:489-95.

15. Quetin-Leclercq J, Bouzahzah B, Pons A, Greimers R, Angenot L, Bassleer R, Barbason H. Strychnopentamine, a potential anticancer agent. Planta Medica 1993;59:59-62.

16. Tillian M, Wintersteiger R, Gubitz G. Systemic application of cysteine for pharmacokinetic studies of tumor models in rat and mice [Abstract]. Arzneimittelforschung 1996;46:640-2
17. Tsumura M, Yoshiga K, Takada K Enhancement of antitumor effect of 5fluorouracil combined with hypertermia on Ehrlich ascites tumor in vivo. Cancer Res 1988;48:3977-80.

18. Lai BT. Antitumor effect of methylene blue in vivo [Abstract]. Chun Hua Chung Liu Tsa Chih 1989;11:98-100.

19. Saha S, Ghosh A. Changes in plasma gangliosides in relation to tumor growth modified by vitamin A. Cancer Lett 1991;56:251-8.

20. Das S, Banerjee S, Gupta JD. Experimental evaluation of preventive and terapeutic potencial of lysozyme. Chemoterapy 1992;38:350-7.

21. Frussa-Filho R, Monteiro MC, Soares CG, Decio RC. Effects of haloperidol, bromocriptine and amphetamine on the development of Ehrlich ascites carcinoma in mice. Pharmacology 1992;45:58-60.

22. Scheller S, Krol W, Skirmuntt K, Zydowicz G, Shani J. Antitumoral effect of bleomycine and dolomite combination treatment, in mice bearing Ehrlich ascite carcinoma. Z Naturforsch Sect C Biosci 1993;49:818-20.

23. Kageyama K, Onoyama Y, Otani S, MatsuiYuasa I, Nagao N, Miwa N. Enhanced inhibitory effects of hypertermia combined with ascorbic acid on dna syntesis in Ehrlich tumor cells grown at a low cell density. Cancer Biochem Biophys 1995;14:273-80.

24. Andreani A, Bossa R, Fraccari A, Galatulas I, Ninci MA, Rambaldi M. Antitumor activity of an alkylating derivate of dipiridamole. Anticancer Res 1996;16:1831-3.

25. Gotthardt R, Neininger A, Gaestel M. The anti cancer drug cisplatin induce $\mathrm{H} 25$ in Ehrlich ascite tumor cells by a different from transcriptiomal simullation. Int J Cancer 1996;66:790-5.

26. Mizuuchi H, Yoshiga K, Sakurai K, Tsumura M, Takada K. Antitumor effect of carboplatin combined with hypertermia on Ehrlich ascites tumor in vivo. Anticancer Res 1996;16:381-7.

Saad-Hossne R, Hossne WS, Prado RG. Neoplasic ascite: effects of phenol, glycerin and acetic in Ehrlich ascite tumor. Acta Cir Bras [serial online] 2003 Nov-Dec;18(6). Available from URL: http://www.scielo.br/acb.

ABSTRACT - Purpose: To analyze the effects of phenol, glycerin and aceter acid in Ehrlich ascite tumor. Methods: For this 283 mouse were used and divided into 2 protocols (with and whithout tumor) wich were treated with $0,25 \mathrm{ml}$, $0,10 \mathrm{ml}, 0,05 \mathrm{ml}$ of the test solution and with $0,25 \mathrm{ml}$ of saline solution. The sacrifice occurred after 3 and 6 days of treatment; the effects of these solutions were analysed through diferential cell scoring in the ascite liquid. Results: It was observed that in the animals with tumor, the number of tumoral cells dicresead and the number of inflamatory cells increased, while in the animals without tumor the solution cause an increase in the number of inflamatory cells. Conclusion: This solution cause an increase of inflammatory cells and decrease of tumoral cells in ascite fluid.

KEY WORDS - Carcinoma, Ehrlich Tumor. Combined modality therapy. Ascites.

Conflito de interesse: nenhum

Correspondência: Fonte de financiamento: nenhuma

Prof. Dr. Rogério Saad-Hossne

Departamento de Cirurgia e Ortopedia

Faculdade de Medicina de Botucatu - UNESP

18618-970 Botucatu - São Paulo

Tel: (14)3811-6269

cgeral@fmb.unesp.br

Data do recebimento: 15/08/2003

Data da revisão: 02/09/2003

Data da aprovação: 25/09/2003 